\title{
New Insights into Retail Space and Format Planning from Customer Tracking Data
}

\section{Document Version}

Accepted author manuscript

Link to publication record in Manchester Research Explorer

\section{Citation for published version (APA):}

Newman, A., Yu, D. K., \& Oulton, D. (Accepted/In press). New Insights into Retail Space and Format Planning from Customer Tracking Data. Journal of Retailing and Consumer Services, 9(5), 253-258. [1].

\section{Published in:}

Journal of Retailing and Consumer Services

\section{Citing this paper}

Please note that where the full-text provided on Manchester Research Explorer is the Author Accepted Manuscript or Proof version this may differ from the final Published version. If citing, it is advised that you check and use the publisher's definitive version.

\section{General rights}

Copyright and moral rights for the publications made accessible in the Research Explorer are retained by the authors and/or other copyright owners and it is a condition of accessing publications that users recognise and abide by the legal requirements associated with these rights.

\section{Takedown policy}

If you believe that this document breaches copyright please refer to the University of Manchester's Takedown Procedures [http://man.ac.uk/04Y6Bo] or contact uml.scholarlycommunications@manchester.ac.uk providing relevant details, so we can investigate your claim.

\section{OPEN ACCESS}




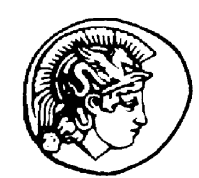

PERGAMON

\title{
New insights into retail space and format planning from customer-tracking data
}

\author{
Andrew J. Newman*, Daniel K.C. Yu, David P. Oulton \\ Department of Textiles, University of Manchester, Institute of Science and Technology, P.O. Box 88, Manchester M60 1QD, UK
}

\begin{abstract}
Recording and understanding the behaviour of customers is paramount and a key factor influencing the success of any retail business. This paper reports the initial stages of an EPSRC funded research project, which presents a new methodological approach to analysing in-store customer behaviour with a view to optimising space and store performance. Using existing in-store CCTV cameras from a major clothing discount retailer, consumers are tracked to detect patterns of behaviour. Analysis of these "realtime" data exhibited flaws in the arrangement of customer service facilities, and insight into the problems associated with merchandise return policies. Understanding these customer processes and movement patterns thus helped the retail collaborator maximise the performance of the store. (C) 2002 Elsevier Science Ltd. All rights reserved.
\end{abstract}

\section{Introduction}

Retail store settings are interesting places, and among other things, the varied arrangements of fittings and general architecture of the layouts, attract or repel consumers. Retail institutions spend huge sums in the pursuit of improved multi-dimensional formats and design solutions, to lure customers into their stores. Measuring consumer behaviour is one of the best methods to understand a good deal more about the specific facets of settings and how customers interface psychologically with them. Investigating these phenomena is an enticing area of consumer research, and has been the subject of research studies (Kotler, 1973; Donovan and Rossiter, 1982; Zimmer and Golden, 1988; Donovan et al., 1994; Baker and Parasuraman, 1994). Effective store characteristics, and their ability to induce positive consumer behaviour, are however resistant to measurement. This has promoted many studies to adopt qualitative approaches in an attempt to uncover the multiplicity of factors driving consumer actions.

Prior research into customer behaviour generally involves intense or prolonged contact with a field situation, and through a deeper understanding or social interaction with (actors) consumers. For example,

\footnotetext{
*Corresponding author. Tel.: +44-161-200-4150; fax: +44-161-2004126.

E-mail address: andrew.newman@umist.ac.uk (A.J. Newman).
}

Barker (1965) and Wells and Lo Scutio (1966) drew on the observer's interpretation of actions for the subsequent analysis. Similarly, work by Ericsson and Simon (1984) used protocol analysis to provide insight from participants' personal recollections of the process, either during or immediately following behaviour. Focusing on merchandise and the appearance of the store, Hildebrandt (1988) asked customers to recall six image attributes influencing their actions. Other work using an ethnographic approach and orientation (McGrath, 1989) has attempted to tap into the complexity of consumer situations, by uncovering meaning from interaction with social actors. Although useful at a conceptual level, approaches such as these have proved of less practical value for retailers. This is largely because there are few clear links between consumers' evaluations of store layouts and shopping behaviour.

When entering the store customers tend not to (mentally) evaluate the individual aspects of the layouts, or consciously identify the attributes that engage their attention. By and large, people are unaware of such factors, and typically fail to provide researchers with detailed and exact answers when asked to recall and evaluate their behaviours. Most studies have utilised either manual observational techniques, or survey and interviews that rely on consumers' retrospective recall. As previously suggested, this approach can introduce a high degree of unreliability into the study. Attempts to engage in deeper analysis and analytical interpretation of consumer behaviour using phenomenological 
approaches (e.g. Dodd et al., 1998 and Birtwistle et al., 1998) have provided great insight in particular retail applications. However, these are by definition inherently subjective and therefore lack the generalisability necessary to provide widespread solutions for practitioners.

More recent work in the field (Newman et al., 1995a, b; Newman, 1998) has demonstrated that interviewer bias, the use of manual counting and traditional methodologies in retailing, fundamentally weakens the validity of any data. In an attempt to address this shortfall, this paper proposes that unobtrusive observation through video collection substantially overcomes this problem. Recording customer behaviour using video footage and computer software from within the retail environment will provide an essential, "objective" record of movement patterns (Newman, 1999 and Church and Newman, 2000). This technique provides a reliable "snapshot" of actual behaviour, and is therefore a basis for establishing useful and commercial retail strategy.

The capture of customer movement using computerbased technology (in-store tracking) has been the focus of limited research (Kirkup, 1998), and lacks a developed and robust approach. Research reported in this paper builds on this prior work in an attempt to fully operationalise video capture of customer movement from retail store CCTV installations. To this end, the study advances this new methodological approach as a means of analysing in-store customer behaviour from real-time data.

\section{Data collection}

After successfully obtaining funding from the Engineering and Physical Sciences Research Council, the authors secured the services of a major clothing discount retailer known for their dynamism and attitude towards store design and development. This collaboration made it possible for the project to record and analyse customer movement patterns in an actual store environment. However, the commercial collaborators imposed restrictions on the work stressing that data collection must not interfere with store business. To simplify the research design, a new store and recent roll out located in the North East of England became the subject of measurement. This was an important consideration as the location and type of store influenced the provision and level of equipment specification available on the test site.

Data collection was automatic using specially (and newly) installed ceiling mounted CCTV security cameras connected to time-lapsed video recording equipment. Instore, the areas chosen for analysis were the entrance, exit, checkouts and customer service area. All cameras were fixed with no panning or zooming functions. Only one of the cameras produced colour images with the remainder in black and white format. Each was connected to a multiplex device, which was then linked to a time-lapse videocassette recorder. A 3-h VHS videotape was used to record 24-h continuous store operation. Fig. 1 illustrates the video tracking set-up.

As mentioned, the cameras were of the type normally used by the retailer for security purposes, and earlier trials found that the focusing and angle of the in-store cameras were critical. Independent research $\mathrm{Yu}$ and Oulton (2000) has demonstrated that the quality of the image generated by the video cameras was vital to successful analysis. Because of the time-lapse function, the system only provided image quality with an approximate sampling rate of 5 frames per second. This created a problem for the customer-tracking objective, as the customer movement appeared jerky and was therefore difficult to analyse.

The raw data was digitised by using a video capture card, and stored as AVI movie format for later analysis. Data storage posed a real problem as just three minutes recording, with resolution $320 \times 240$ pixels in 24 bits true colour, has a file size of around $400 \mathrm{MB}$. This presented some problems for data storage, as the size of

\section{Up to 16 CCD cameras}

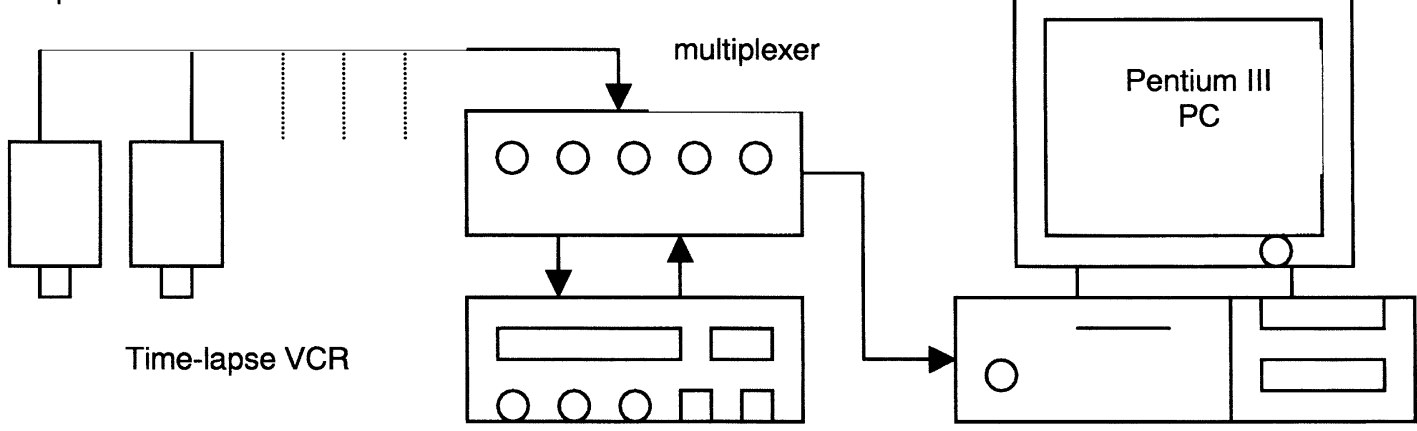

Fig. 1. Diagrammatic representation of video tracking set-up. 
the hard disk must be at least $20 \mathrm{~GB}$ in order to have the capacity to analyse $1 \mathrm{~h}$ of video footage. This study used a $733 \mathrm{MHz}$ Pentium III personal computer with $128 \mathrm{MB}$ RAM, and a portable zip drive for backup data. To save on hard disk space, the AVI movie formatted files were compressed into MPEG movie format. However, this process has the disadvantage of decreasing the quality of the movie, whilst taking rather long time to compress it. The authors found that it was better to retain the footage in AVI format for subsequent analysis.

\subsection{Customer counting and motion estimation}

Tracking cannot be achieved without performing motion detection. The presence of a face, or similar distinctive image element, may be inferred by detecting differences between the current image and a reference image, by searching for large skin coloured areas or by searching for face-shaped regions (Morris, 2000). However, a hybrid approach, which is based on both skin colour information and shape of a face, was used in this project in order to increase the accuracy of counting. With this hybrid approach, the computer will not identify other large skin areas such as the arms and legs of one customer in relation to another. It is also necessary to take into account the fact that customers tend not to walk in an upright manner looking horizontally forward. In reality, the shape of a customer's head from the security camera point of view is always changing.

The traditional method for motion detection is based on frame difference, which is the subtraction of pixel values held in two different frames. However, it is only suitable for detection of continuous object movement in low speed. In the case of time-lapse video recording, continuously moving the position of the customer in each frame is relatively wide apart due to the sampling rate which is only 5 frames per second. The object (in this case a customer) moves forward from one frame to the next creating a small displacement. When pixel values from frame 1 are subtracted from frame 2, the (minimal) change is shown on screen. If the object makes a very small movement, it is possible to subtract frame 1 from another frame to achieve an acceptable detection result. When the video footage is based on time-lapse recording method with several cameras connected to a multiplex device, the same test object moves forward with a much larger displacement. The difference between frames is too far apart, which may result in detecting two changes rather than the incremental change required.

The time-lapse effect created an inconsistency that necessitated the development of a new algorithm. This used the principle of motion estimation. Mattison (1994) defined motion estimation as a process to determine which pixel blocks contain information representing parts of the image that have moved and how far they have moved. Thus by taking a pair of images from our video sequence and dividing each into a series of subimages (e.g. $10 \times 10$ blocks of pixels), it was possible to determine which blocks represent parts of the picture that have moved and which have remained static. This block matching process is conceptually quite simple although it may be fairly expensive in terms of computation time. By mapping the block from the previous image to various positions on the new image, and calculating the mathematical difference at each position, it is possible to determine mathematically whether the difference at a given location is low enough to constitute a match. It is very time consuming to search a large area of the image for each motion vector calculated. A digital mask filter was therefore developed to control the search area. The radius of the digital mask filter is a key factor in the matching process.

\subsection{Multi-customer tracking}

The above algorithm can be used to track several customers inside the store at the same time. Two examples are provided in Figs. 2 and 3 below for illustrative purposes. Fig. 2 is based on time-lapse video footage and Fig. 3 on continuous video footage. For identification purposes, each entity in the video footage is given a numerical value to represent the point from which they were first tracked. Fig. 3 (below) illustrates a second example, which is based on continuous highquality video footage. This provides a more complete picture of customer behaviour than Fig. 2.

In Fig. 2, staff " 0 " and staff " 1 " are seen walking in front of the customer service counter. Customer "2" walks from the entrance area into the store. Fig. 3 shows eight customers being tracked at the same time using a high-quality camera. Track " 0 " depicts a male subject walking in a relatively straight line and subsequently turning to observe something of interest on the supermarket shelving. At this point the subject stopped to browse; a factor that is represented by a dwell period. Entities "1" and "2", are two young children which explains the wavy patterns of movement, as children usually display excitement and erratic behaviour during the shopping experience.

\section{Results and analysis}

\subsection{Key variables}

A number of important variables emerged from the initial stages of the investigation that informed the design of the data collection process. Factors such as the quality of the image generated by the video cameras was vital to the analysis. For example, the focusing and 


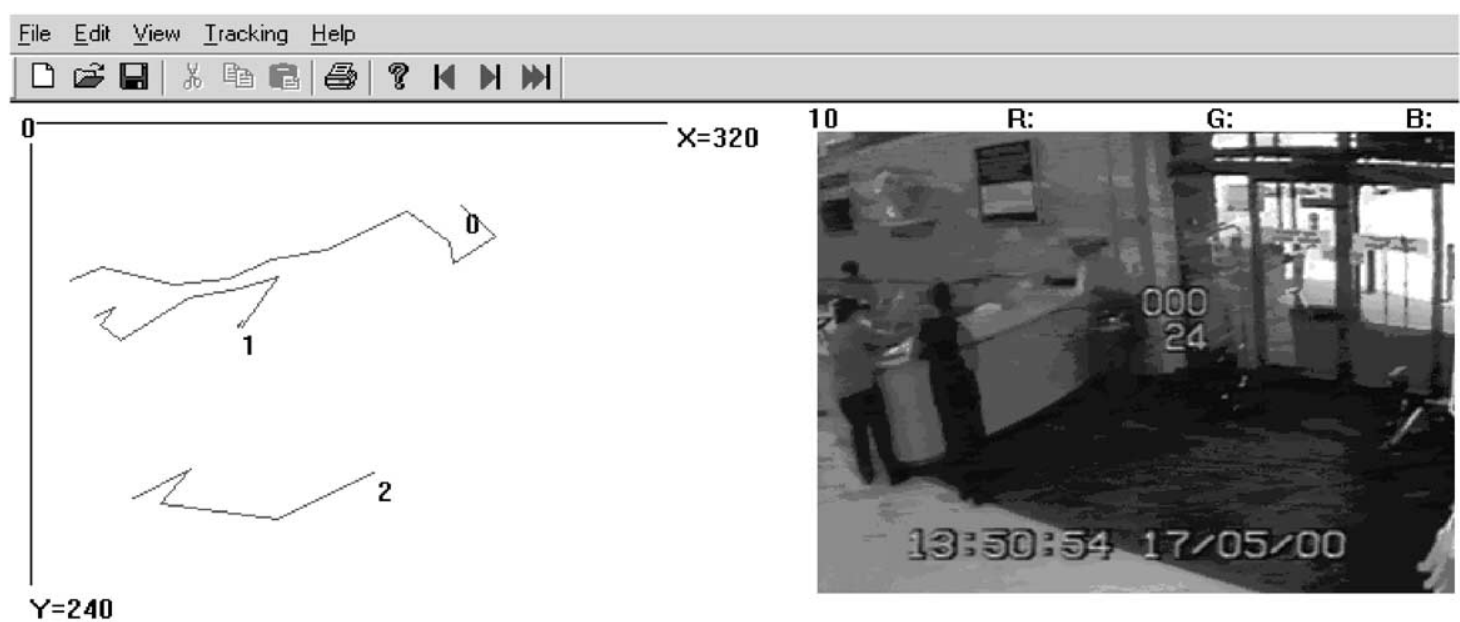

3D View

Fig. 2. Multi-customer tracking based on time-lapse video footage.

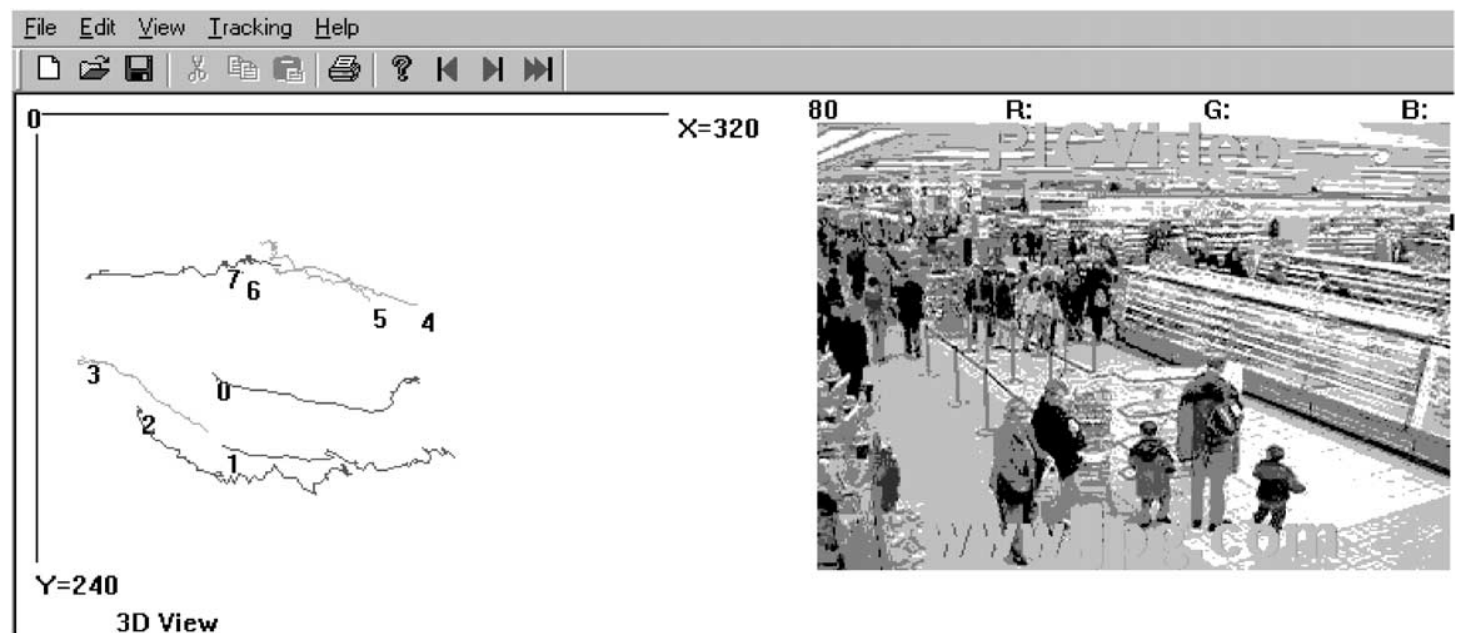

Fig. 3. Multi-customer tracking based on continuous video footage.

angle of the in-store cameras was critical. Equally important was the recording length of videotapes provided as these had to sufficiently cover store opening times. Other issues such as the lighting emitted from outside entrances, varied the degree to which images could be clearly segmented using the motion estimation software.

Data from 7 days operation were subsequently analysed that necessitated different algorithms for image segmentation and threshold selection. This reflected the changing environment of the store during the period of data collection. The data in Table 1 below illustrates that customer arrival patterns tend to vary with the time of day, and day of week. A "manual counting" verification (see Table 1 below), which involved observing video footage and systematically counting customers as they cross the field of view, helped to evaluate the integrity of the data. The "program counting" figures represent the automatic count calculated by the software developed for this research project.

Column one (Table 1) contains the number of customers that arrived during the first day of the sales (26th April 2001). This shows not surprisingly an increase of $63 \%$ in footfall when compared with the number of customers arriving on a normal day's operation (e.g. 25th April 2001). Following the sale period, marked by increased merchandise sales, the volume of returns rose by more than $300 \%$ by the second day of the sales. This fact is borne out by the large number of customers arriving at the customer service desk, on the day subsequent to the sale period (see Fig. 2 above for an illustration of the customer service desk and store entrance). This phenomenon may suggest a number of factors. For example, customers could have purchased merchandise they did not really 
Table 1

Results from manual and automatic counting

\begin{tabular}{|c|c|c|c|c|c|c|c|}
\hline \multicolumn{8}{|c|}{ (a) Customer count at store entrance } \\
\hline Date & $30 / 04 / 01$ & $1 / 5 / 01$ & $25 / 04 / 01$ & $26 / 04 / 01$ & $27 / 04 / 01$ & $28 / 04 / 01$ & $29 / 04 / 01$ \\
\hline Day & Monday & Tuesday & Wednesday & Thursday & Friday & Saturday & Sunday \\
\hline Manual count & 1422 & 1232 & 1295 & 2047 & 1732 & 2398 & 2022 \\
\hline Program counting & 1295 & 1187 & 1177 & 1937 & 1604 & 2246 & 1950 \\
\hline \multicolumn{8}{|c|}{ (b) Customer count at service desk } \\
\hline Date & $30 / 04 / 01$ & $1 / 5 / 01$ & $25 / 04 / 01$ & $26 / 04 / 01$ & $27 / 04 / 01$ & $28 / 04 / 01$ & $29 / 04 / 01$ \\
\hline Day & Monday & Tuesday & Wednesday & Thursday & Friday & Saturday & Sunday \\
\hline Manual count & 103 & 71 & 45 & 74 & 149 & 82 & 90 \\
\hline Program counting & 93 & 65 & 50 & 71 & 129 & 75 & 83 \\
\hline \multicolumn{8}{|c|}{ (c) Customer count at cash desk } \\
\hline Date & $30 / 04 / 01$ & $1 / 5 / 01$ & $25 / 04 / 01$ & $26 / 04 / 01$ & $27 / 04 / 01$ & $28 / 04 / 01$ & $29 / 04 / 01$ \\
\hline Day & Monday & Tuesday & Wednesday & Thursday & Friday & Saturday & Sunday \\
\hline Manual count & 861 & 772 & 650 & 1096 & 935 & 1613 & 1401 \\
\hline Program counting & 796 & 704 & 509 & 1021 & 814 & 1489 & 1264 \\
\hline \multicolumn{8}{|c|}{ (d) Customer count at exit } \\
\hline Date & $30 / 04 / 01$ & $1 / 5 / 01$ & $25 / 04 / 01$ & $26 / 04 / 01$ & $27 / 04 / 01$ & $28 / 04 / 01$ & $29 / 04 / 01$ \\
\hline Day & Monday & Tuesday & Wednesday & Thursday & Friday & Saturday & Sunday \\
\hline Manual count & 1221 & 950 & 1121 & 1822 & 1603 & 2164 & 1770 \\
\hline Program counting & 1173 & 911 & 1079 & 1728 & 1569 & 2072 & 1721 \\
\hline
\end{tabular}

need, or did not have time or the space to examine before purchase. Other possibilities include faulty goods, poor designs, wrong fittings, etc.

Analysis of the arrival and departure data appeared to show a conflict between the number of customers arriving at the store entrance, and the number of customer leaving via the exit. The latter appears to consistently greater and, as such, suggests that substantial numbers of customers entered the store and simply left by the same means. This more than likely reflects the customers that entered the store to visit the customer service desk (located at store entrance) and left immediately after refund or a related service.

\section{Conclusion and implications}

This paper has described the data collection mechanism and ways in which the data may be processed to measure in-store customer behaviour. With suitable camera positions, the motion estimation algorithm could track customers from the moment of their arrival at the entrance to the minute they leave the store. This represents a major breakthrough in academic and retail research as it provides a new methodological approach to retail store designs and formats.

It is highly important to understand customer traffic flows inside retail stores, as these patterns can help to analyse how the layout and general format can influence the shopping experience. From research in retailing, marketing and environmental psychology we know that a store's atmosphere is likely to positively or negatively influence a shopper's emotional state. This in turn can lead to increased or decreased shopping activity. For example, consumers' moods which are made up of the three emotional states: pleasure, arousal and dominance, have been shown to be influential on the way in which consumer spends time in the store (Donovan and Rossiter, 1982).

In general, retailing research provides retailers with few practical solutions that are likely to enhance the shopping experience. Practitioners seek out reasons to explain issues such as hot and cold spots, and require new knowledge to support the creation of store interiors. In general, there is a "relative paucity (italics added) of information" for retailers to draw on (Israel, 1994). Of course there is an abundance of anecdotal evidence (cases and success stories) to suggest that certain design solutions do work, but few studies demonstrate why or how they work. With an accurate knowledge of layouts and fixtures, and a theoretical understanding of the impact of such factors, it will be possible to record and predict the influence of design features like fixtures, entrances and walkways on customer behaviour.

For example, this study demonstrated and explained why subjects tend to dwell or cluster round a key location. Parallels may be drawn with work in the biological sciences (see Wratten, 1994), and this presents an opportunity to take a more developed approach to problems of retail crowding. Small and calculated changes to layouts can help to alleviate shopping stress 
(Aylott and Mitchell, 1998), and enhance the shopping experience for the customer. This demonstrates the importance of collecting data and tracking customers around retail stores.

Using CCTV footage, the customer counting algorithm developed for this study can detect number of customers anywhere in the store, and at any period of time. This can achieve $94.5 \%$ accuracy when counting customers in-store. Future work will collect these categorical data routinely during store opening hours. Probability calculations of these "real-time" data will identify a very accurate picture of store activity. This may, for example, demonstrate why customer traffic clusters round the middle of the store, with low footfall numbers in other areas. Using this categorical customer movement data, and as suggested by Newman (1999) and Church and Newman (2000), it is possible to map out and visualise customer activity in sample stores. Retail partners can then strategically arrange store architecture according to the behaviour their management wishes to evoke (e.g. circulation, left or right movement, accessibility). Ultimately, this will lead to greater access to merchandise and increased conversion (sales).

The new methodological approach reported in this paper uses real-time data and computerised movement tracking to experiment with and re-engineer store layouts. Statistical data thus provides the basis for planning the design of merchandise placement and instore, and the arrangement of fixed and movable fittings. Trends and patterns of movement will help with staff planning and the merchandise replenishment processes. For the customer, the intention is to lessen shopping stress induced by ambiguous settings. An example of this is when a consumer is faced with frequent or unexplained (in terms of signage) layout changes, and/or changes in merchandise position so creating major disincentives to shop. Clear and legible store designs, incorporating aisle design fixtures and merchandise, will reduce the uncertainty that consumers associate with shopping in large floor spaces. Customers can focus on the purchase rather than developing their navigation skills. A retailer can thus maximise sales volume by arranging, manipulating and customising the store format. This is, after all, the retailer's overall goal.

\section{References}

Aylott, R., Mitchell, V.-W., 1998. An exploratory study of grocery shopping stressors. International Journal of Retail and Distribution Management 26 (9), 362-373.
Baker, J., Parasuraman, D.G.A., 1994. The influence of store environment on quality inferences and store image. Journal of the Academy of Marketing Science 22 (4), 328-339.

Barker, R.G., 1965. Explorations in ecological psychology. American Psychologist 20, 1-14.

Birtwistle, G., Clarke, I., Freathy, P., 1998. Customer decision-making in fashion retailing: a segmentation analysis. International Journal of Retail and Distribution Management 26 (4), 147-154.

Church, I., Newman, A.J., 2000. Simulating production-line service operations: a systematic approach to process management. The British Food Journal 102 (5/6), 398-405.

Dodd, C.A., Clark, I., Kirkup, M.H., 1998. Camera observations of customer behaviour in fashion retailing: methodological propositions. International Journal of Retail and Distribution Management 26 (8), 311-317.

Donovan, R.J., Rossiter, J.R., 1982. Store atmosphere: an environmental psychology approach. Journal of Retailing 58, 34-57.

Donovan, R.J., Rossiter, J.R., Marcoolyn, G., Nesdale, A., 1994. Store atmosphere and purchasing behaviour. Journal of Retailing 70 (3), 283-294.

Ericsson, K.A., Simon, H.A., 1984. Protocol Analysis: Verbal Reports as Data. MIT Press, Cambridge, MA.

Hildebrandt, L., 1988. Store image and the perception of performance in retailing. Journal of Business Research 17. \par.

Israel, L.J., 1994. Store Planning/Design. Wiley, New York.

Kirkup, M., 1998. Assessing the role of electronic customer tracking in retail information systems: Experiences in UK fashion retailing. Proceedings of the Fifth International Conference on Recent Advances in Retailing and Services Science, Baveno, Italy, August.

Kotler, P., 1973. Atmospherics as a marketing tool. Journal of Retailing 49 (4), 48-65.

Mattison, P.E., 1994. Practical Digital Video with Programming Examples in C. Wiley, New York.

McGrath, M.A., 1989. An ethnography of a gift store: trappings, wrappings, and rapture. Journal of Retailing 65 (4), 421-429.

Morris, T., 2000. Multimedia systems: delivering, generating and interacting with multimedia. Springer, Berlin.

Newman, A.J., 1998. Consumption and the airport setting: find the time to go shopping. Proceedings of the Fifth International Conference on Recent Advances in Retailing and Services Science, Baveno, Italy, August.

Newman, A.J., 1999. Devising a new methodological approach to retail format planning. Proceedings of the Sixth International Conference on Recent Advances in Retailing and Services Science, Puerto Rico, July.

Newman, A.J., Davies, B.J., Dixon, G., 1995a. A theoretical model approach to terminal shopping syndrome: a future challenge for UK airport operators? Proceedings of the 24h European Marketing Academy Conference, ESSEC, Paris, May.

Newman, A.J., Davies, B.J., Dixon, G., 1995b. Identifying the social and physical environs affecting persons in UK airports: An archetypal model of consumption advanced. Marketing Education Group Conference, University of Bradford, July.

Wells, W.D., Lo Scutio, L.A., 1966. Direct observation of purchasing behaviour. Journal of Marketing Research 3, 227-233.

Wratten, S.D., 1994. Video Techniques in Animal Ecology and Behaviour. Chapman \& Hall, London.

Yu, K.C.D., Oulton, D.P., 2000. Colour difference acceptability for calibrated digital images. The Imaging Science Journal 48 (4), $165-176$.

Zimmer, M.R., Golden, L.L., 1988. Impressions of retail stores: a content analysis of consumer images. Journal of Retailing 64 (fall), 265-293. 